\title{
Model Test and Numerical Simulation Analysis on Freezing Effect of Different Freezers in Freeze-Sealing Pipe-Roof Method
}

\author{
Haibing Cai $\mathbb{D}^{1},{ }^{1}$ Yujie Liu, ${ }^{1}$ Rongbao Hong $\mathbb{D}^{1},{ }^{1}$ Mengkai Li ${ }^{(D)},{ }^{1}$ Zongjin Wang, ${ }^{2}$ \\ and Hanglong Ding \\ ${ }^{1}$ School of Civil Engineering and Architecture, Anhui University of Science and Technology, Huainan, Anhui 232001, China \\ ${ }^{2}$ China Coal Special Drilling Engineering Co., Ltd., Hefei 230001, China
}

Correspondence should be addressed to Haibing Cai; haibingcai@163.com

Received 29 October 2021; Accepted 21 December 2021; Published 27 January 2022

Academic Editor: Xinyu Ye

Copyright (C) 2022 Haibing Cai et al. This is an open access article distributed under the Creative Commons Attribution License, which permits unrestricted use, distribution, and reproduction in any medium, provided the original work is properly cited.

\begin{abstract}
The Gongbei Tunnel Project is a key phased project of the Zhuhai Connection Line of the Hong Kong-Zhuhai-Macao Bridge, and the freeze-sealing pipe-roof (SFPR) method was first applied successfully. During this period, in order to obtain the best arrangement of freezers, three configurations, that is, solid pipe with circular freezer (SCF), empty pipe with double circular freezer (EDCF), and empty pipe with special-shaped freezer (ESF), were designed to analyze their freezing effects. The model test results show that the freezing temperature fields excited by different arrangements of freezers are obviously different, and the freezing effect of ESF is the best. The numerical simulation results indicate that the temperature cloud diagram of SCF at $42 \mathrm{~h}$ is butterflyshaped after opening the limit pipes, and the temperature cloud diagrams of ESF and EDCF are the same as the model test results. However, the processing method of ESF is relatively complex, which adopts arc angle steel welding requiring a lot of reverse welding and high welding quality. Eventually, EDCF is recommended to ensure the quality of frozen walls due to its lower cost and better freezing effect. This research plays a basic role in the implementation of the freeze-sealing pipe-roof method.
\end{abstract}

\section{Introduction}

With the further progress of urbanization, the development and utilization of urban underground space are facing an increasingly harsh construction environment [1], especially, it is more severe during the construction of urban tunnels in shallow and water-rich strata. Under this background of urban construction, the artificial ground freezing (AGF) method has been widely used due to its environmental friendliness [2]. So far, projects using AGF technique, such as the cross-passage construction of Zhuji Intercity Rail Transit, China [3], the turn-back tunnel construction of Guangzhou Metro Line 3 Tianhe Station, China [4], the tunnel construction of Nanjing Metro Line 2 Xinjiekou Station, China [5], and so on, have all achieved good social benefits. Besides, the frozen wall formed by the AGF method mainly plays a role in water sealing [6], and its bearing capacity is relatively weak compared with the steel pipe jacking structure. Some successful applications of steel pipe jacking structure in the tunnel excavation are as follows: rectangular pipe jacking construction between two parallel tunnels in Nanjing, China [7], four parallel pipe jacking construction under Guan River, China [8], two steel pipe jacking construction under Yangtze River, China [9], and so on. These presupporting methods provided good construction conditions for tunnel excavation but exposed the weakness of water sealing, especially in long distance curved pipe-jacked projects. $\mathrm{Hu}$ et al. [10] have been committed to combining the two construction methods to obtain better engineering application value, and four research methods, that is, theoretical analysis [11], numerical simulation [12], model test [13], and field monitoring [6], have been implemented to verify the feasibility of this new construction method. This novel method is named freezesealing pipe-roof (SFPR) method, an auxiliary method combining the pipe-roof method and artificial freezing 
method, where the steel pipe-roof mainly plays a role in load bearing and the frozen soil curtain mainly plays a role in water sealing. Benefitting from the support of the above research, SFPR has successfully solved many construction problems of the Gongbei tunnel, including shallow buried depth, large section [14], abundant water, large curvature, etc.

However, there are still many possibilities available for the research of freezers arranged in steel pipes, such as the shape of the freezer, number of the freezer, location of the freezer, and so on. Four mainstream methods can be used to study these problems; they are theoretical analysis, numerical simulation, model test, and field monitoring. Qi et al. [15] studied the temperature field expansion of basinshaped freezing method through physical model test and numerical simulation; it shows the gradual development of freezing from backwater surface to front water surface under seepage condition. Liu et al. [16] studied the freezing effect considering the pipe inclination in the unit cell model by prescribing various values of freeze pipe spacing based on a coupled thermohydraulic finite element method. Vitel et al. [17] studied the heat transfer between the freeze pipe and the surrounding ground and established a developed model to conduct parametric studies on operating conditions, refrigerant type, system geometry, or ground properties through numerical simulation. It is not difficult to see that model test and numerical simulations are more popular.

In view of this, this paper studies the distribution law of the freezing temperature field excited by different arrangements of freezers, based on the SFPR method construction of the Gongbei tunnel. Specifically, the model test and numerical simulation of three configurations are designed by using the wet-heat similarity criterion. They are solid pipe with circular freezer (SCF) freezing configuration, empty pipe with double circular freezer (EDCF) freezing configuration, and empty pipe with special-shaped freezer (ESF) freezing configuration, respectively. All the basic research is the expansion and enrichment of the SFPR technique, which also provides a favorable reference for the follow-up projects similar to the Gongbei tunnel.

\section{Project Overview}

As a critical part of the Zhuhai connection highway of the Hong Kong-Zhuhai-Macao Bridge project, the Gongbei tunnel is located in the Xiangzhou District of Zhuhai City and has a length of $2.74 \mathrm{~km}$. That length is divided into an open excavation section of the sea area (1225 m length), an underground excavation section of the port ( $255 \mathrm{~m}$ length), and an open excavation section of the land area $(1229 \mathrm{~m}$ length). Amongst these divisions, the underground excavation section of the port is the largest undercut tunnel in the world, with a buried depth of $4-5 \mathrm{~m}$ and an excavation section area of $337 \mathrm{~m}^{2}$. The plane layout of the underground excavation section of the Gongbei tunnel is shown in Figure 1. Furthermore, this section passes through the Gongbei port with poor geological and sensitive environmental conditions, such as high groundwater level, soft stratum, dense building groups, and mass population flow. It is required not to affect the normal passage of the Gongbei port and normal use of surrounding buildings and underground pipelines during the construction of the Gongbei tunnel.

As a new construction technique that combines the pipe jacking method with the artificial ground freezing method, the freeze-sealing pipe-roof method has been proposed and applied to the construction of the Gongbei tunnel. As shown in Figure 2, 36 steel pipes with a diameter of $1620 \mathrm{~mm}$ are arranged around the Gongbei tunnel, in which the oddnumbered pipes are filled with microexpansive concrete, while the even-numbered pipes are not filled with any materials. Besides, in each odd-numbered pipe, two $\Phi 125 \mathrm{~mm}$ circular freezing pipes are embedded for soil freezing, and one $\Phi 159 \mathrm{~mm}$ limit pipe is embedded to control the scope of the frozen curtain. Correspondingly, two special-shaped freezing pipes are welded on the inner wall of each even-numbered pipe to intensify the soil freezing.

In this paper, a new freezing configuration that empty pipe with a double circular freezer (EDCF) is proposed based on the exiting two freezing configurations (SCF and ESF), and it has the advantages of lower cost and convenient processing. Therefore, it is meaningful to determine the optimal arrangement of freezers from many aspects among these three freezing configurations.

\section{Design of Model Test}

\subsection{Similarity Criterion}

3.1.1. Temperature Field Similarity. The heat conduction equation of the frozen zone and the unfrozen zone is as follows:

$$
\frac{\partial \theta_{n}}{\partial \tau}=a_{n}\left(\frac{\partial^{2} \theta_{n}}{\partial r^{2}}+\frac{1}{r} \frac{\partial \theta_{n}}{\partial r}\right),
$$

where $\theta_{n}$ is temperature; when $n=1$, it is the temperature in the unfrozen zone; when $n=2$, it is the temperature in the unfrozen zone; $\tau$ is time; $a_{n}$ is the thermal conductivity coefficient.

The temperature boundary conditions are as follows:

$$
\left\{\begin{array}{l}
\theta(r, 0)=\theta_{0} \\
\theta(\infty, \tau)=\theta_{0} \\
\theta(\rho, \tau)=\theta_{D} \\
\theta\left(r_{0}, \tau\right)=\theta_{y}
\end{array}\right.
$$

where $\theta_{0}$ is the initial temperature of soil; $\theta_{D}$ is the freezing temperature; $\theta_{y}$ is the brine temperature.

Besides, at the frozen front $(r=\rho)$, the heat balance equation is as follows:

$$
\left.\lambda_{2} \frac{\partial \theta_{2}}{\partial r}\right|_{r=\rho}-\left.\lambda_{1} \frac{\partial \theta_{1}}{\partial r}\right|_{r=\rho}=B \frac{\mathrm{d} \rho}{\mathrm{d} \tau},
$$

where $B$ is the latent heat; $\lambda_{1}$ is the thermal conductivity in the unfrozen zone, while $\lambda_{2}$ is the thermal conductivity in the frozen zone. 


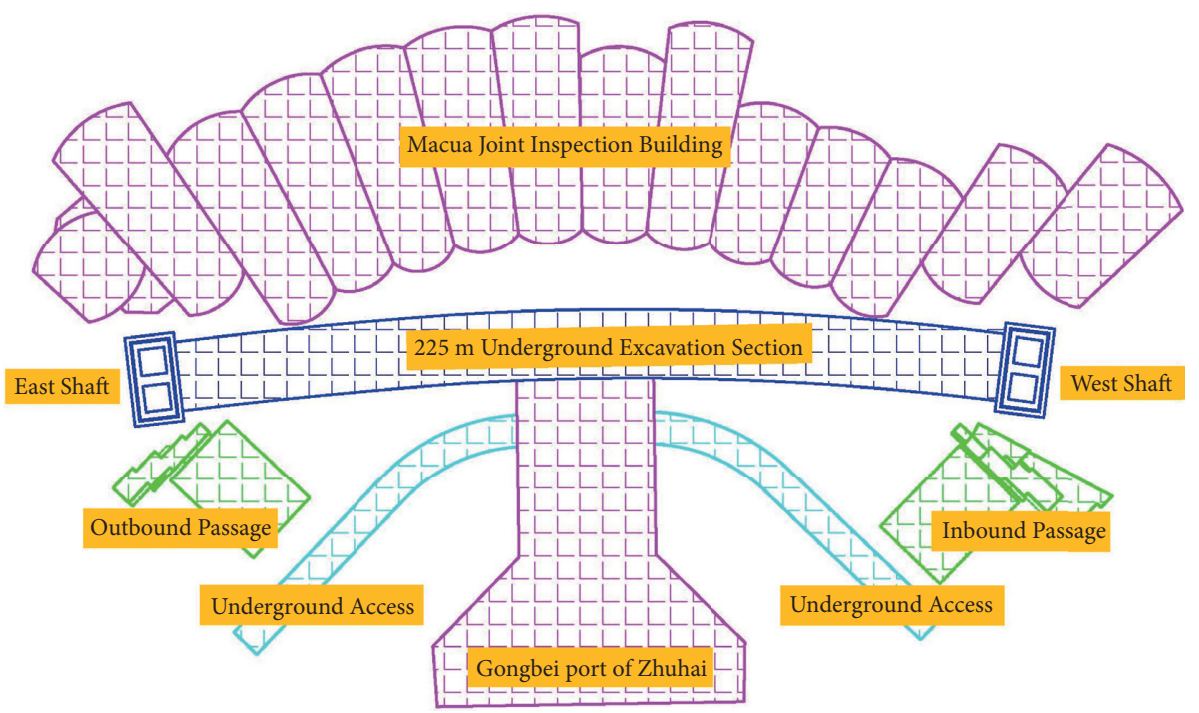

FIgURE 1: Layout chart of the Gongbei undercut tunnel.

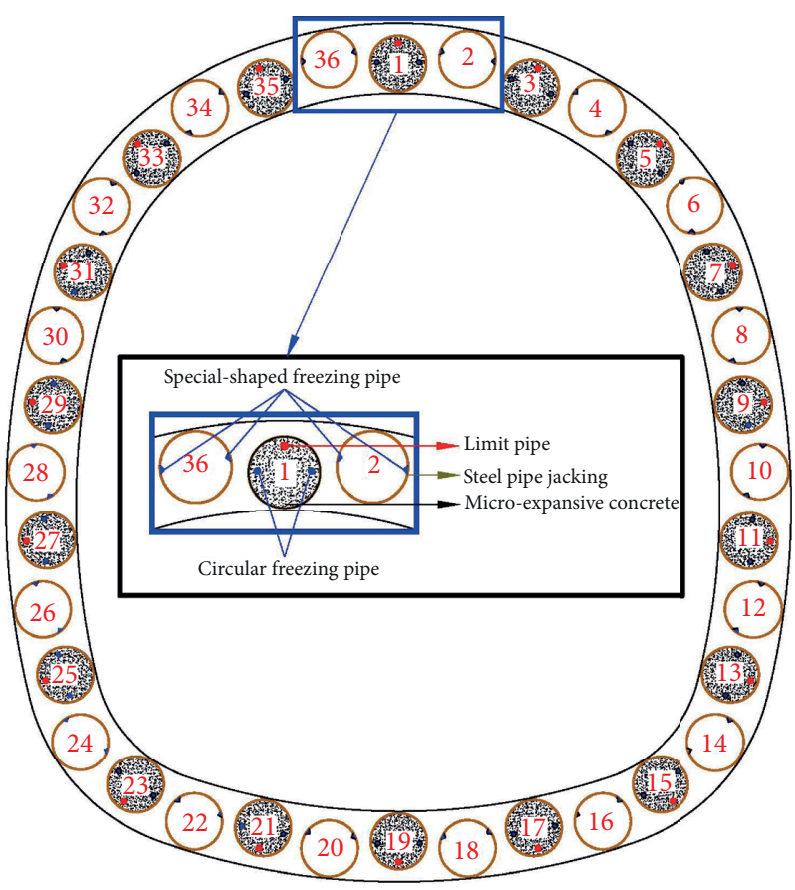

Figure 2: Layout of the pipe curtain.

According to the differential equation of the freezing temperature field, the similarity criterion equation of the freezing temperature field can be obtained as follows $[18,19]$ :

$$
F\left(F_{0}, K_{0}, L_{0}, \theta\right)=0,
$$

where $F_{0}$ is the Fourier criterion, $F_{0}=a \tau / r^{2}, a$ is the temperature diffusivity of sand $\left(\mathrm{m}^{2} / \mathrm{s}\right), \tau$ is time $(\mathrm{h}), r$ is the frozen wall position; $K_{0}$ is Kosovic's criterion, $K_{0}=Q / t c$, $Q$ is the latent heat released when the unit mass of sand is frozen $(\mathrm{J} / \mathrm{g}), t$ is the temperature $\left({ }^{\circ} \mathrm{C}\right)$, and $c$ is the specific heat $(\mathrm{J} /$ $\left.\left(\mathrm{g}^{\circ} \mathrm{C}\right)\right) ; L_{0}$ is the geometric criterion; $\theta$ is the temperature criterion, including sand initial temperature $\theta_{0}$, brine temperature $\theta_{y}$ and freezing temperature $\theta_{D}$.

3.1.2. Moisture Field Similarity. The governing equation of water migration is as follows:

$$
\frac{\partial h}{\partial \tau}=b\left(\frac{\partial^{2} h}{\partial r^{2}}+\frac{1}{r} \frac{\partial h}{\partial r}\right),
$$

where $h$ is the humidity; $b$ is the moisture conductivity coefficient.

The moisture boundary conditions are as follows: 


$$
\left\{\begin{array}{l}
h(r, 0)=h_{0}, \\
h(\infty, \tau)=h_{0}, \\
h(\rho, \tau)=0,
\end{array}\right.
$$

where $h_{0}$ is the initial humidity.

According to the differential equation of the moisture field, the similarity criterion equation of the moisture field can be obtained as follows:

$$
F\left(F_{h}, H_{h}, L_{h}\right)=0,
$$

where $F_{h}$ is the Fourier criterion, $F_{h}=b \tau / r^{2}, b$ is the moisture conductivity coefficient of sand, $\tau$ is time (h), $r$ is the frozen wall position; $H_{h}$ is the humidity criterion, $H=h / h_{0} ; L_{h}$ is the geometric criterion.

3.1.3. Scaling Laws. If the model material is the same as the prototype material, the thermal conductivity scaling law $C_{a}=1$ and the specific heat scaling law $C_{c}=1$. The latent heat scaling law $C_{Q}=1$ can be obtained by guaranteeing that the model soil moisture content is the same as the prototype. It can be deduced from equation (4) that

$$
\begin{aligned}
C_{\tau} & =C_{l}^{2}, \\
C_{t} & =1,
\end{aligned}
$$

where $C_{\tau}$ is the time scaling law, $C_{t}$ is the temperature scaling law, and $C_{l}$ is the geometric scaling law, which is $C_{l}=10$ for this model test. The test discussed in this paper focused on the distribution of the temperature field, providing a comparison of the optimum results of the FSPR process. Because the tests were conducted at a partial scale, the saturated sand used in the test was reformulated according to the nature of the undisturbed soil at the Gongbei Tunnel Project site to ensure the scaling law of materials.

The velocity of saltwater in the freezing tube can be described by the following:

$$
v^{\prime}=C_{l} v
$$

where $v^{\prime}$ is the velocity of saltwater in the freezer of the model, and $v$ is the velocity of saltwater in the freezer of the prototype.

The dimensions of the jacking pipe and freezers are shown in Table 1 according to the geometric similarity ratio. Besides, in the model test, low-temperature brine consistent with the engineering site is selected as the refrigerant. The freezers are sealed and connected with rubber pipes with an inner diameter of $8 \mathrm{~mm}$, and the flow through the single pipe is controlled as $0.5 \mathrm{~m}^{3} / \mathrm{h}\left(0.5 \mathrm{~m}^{3} / \mathrm{h}\right.$ in engineering site), while the velocity of the refrigerant is controlled as $165.8 \mathrm{~m} / \mathrm{min}$ $(16.58 \mathrm{~m} / \mathrm{min}$ in engineering site), according to equation (9).

3.2. Design of Model Box. The test is carried out in the freezing station of the project department of Liuzhuang Mine, China. The size of the test box is $3.3 \mathrm{~m} \times 1.2 \mathrm{~m} \times 1.5 \mathrm{~m}$, and the thickness of the steel plate is $6 \mathrm{~mm}$. The height of the pipe curtain from the bottom of the model box is $520 \mathrm{~mm}$. All the inner surface of the steel plate is laid with foam insulation board with a thickness of $100 \mathrm{~mm}$. The design drawing of the model box is shown in Figure 3.

Figure 4 shows the photographs of three freezing configurations in the model box. Figure 4(a) shows the solid pipe with a circular freezer (SCF), and the steel jacking pipe is filled with a C30 crushed stone concrete. Two circular freezers are symmetrically distributed in the horizontal direction of pipe jacking, while two limiting pipes are symmetrically distributed in the vertical direction of pipe jacking. Figure 4(b) shows an empty pipe with a double circular freezer (EDCF). Four circular freezers are symmetrically arranged in the horizontal position of the pipe jacking and wrapped with cement mortar. Figure 4(c) shows an empty pipe with a special-shaped freezer (ESF). Two special-shaped freezers made of angle steels are symmetrically arranged at the horizontal position of the pipe jacking. After the pipes and test elements are arranged, the saturated sand is backfilled. Meanwhile, the thermodynamic tests are carried out to obtain the water content, dry density, freezing point, thermal conductivity and et al. of the saturated sand, and test results are shown in Table 2.

3.3. Design of Freezing System. Figure 5 shows the lowtemperature circulating brine refrigeration system used in the model test. The temperature of brine circulating in the freezers is controlled as $-21^{\circ} \mathrm{C}$, while the temperature of brine circulating in the limiting pipes is controlled as $7^{\circ} \mathrm{C}$. Each freezing pipe was equipped with an independent switch.

3.4. Design of Monitoring System. Figure 6 shows the temperature monitoring points distributed at the three directions $\left(0^{\circ}, 45^{\circ}\right.$, and $\left.90^{\circ}\right)$ surrounding the SCF, EDCF, and ESF.

The monitoring system adopts the TDS-630 multipoint test system, and the temperature sensor of the thermocouple is selected as the test material. The CW-500 digital temperature measurement system is also used as the second temperature measurement system to ensure measurement accuracy and reliability. The temperature monitoring points of the two temperature sensor systems are arranged in the box in an 'axisymmetric' manner, as shown in Figure 7.

The monitoring time is $0.5 \mathrm{~h}$ (the fastest is $15 \mathrm{~min}$ ) in the early freezing period, and it is adjusted to $1 \mathrm{~h}$ in the late freezing period. Besides, the system is set to automatically collect data, and the monitoring time interval is appropriately extended after data stabilization.

\subsection{Model Test Process}

(1) Before the test, the physical indexes such as moisture content, dry density, freezing temperature, and thermal conductivity of the saturated sand were measured by cutting ring sampling. The test time, ambient temperature, and initial temperature of the sand in the box were recorded before freezing. 
TABLE 1: Dimensions of jacking pipe and freezers.

\begin{tabular}{lcc}
\hline Name & Original dimension $(\mathrm{mm})$ & Model dimension $(\mathrm{mm})$ \\
\hline Pipe jacking (inner diameter) & 1590 & 159 \\
Circular freezer (inner diameter) & 80 & 8 \\
Special-shaped freezer (angle steel) & $125 \times 125$ & $12.5 \times 12.5$ \\
Limit pipe (inner diameter) & 80 & 8 \\
\hline
\end{tabular}

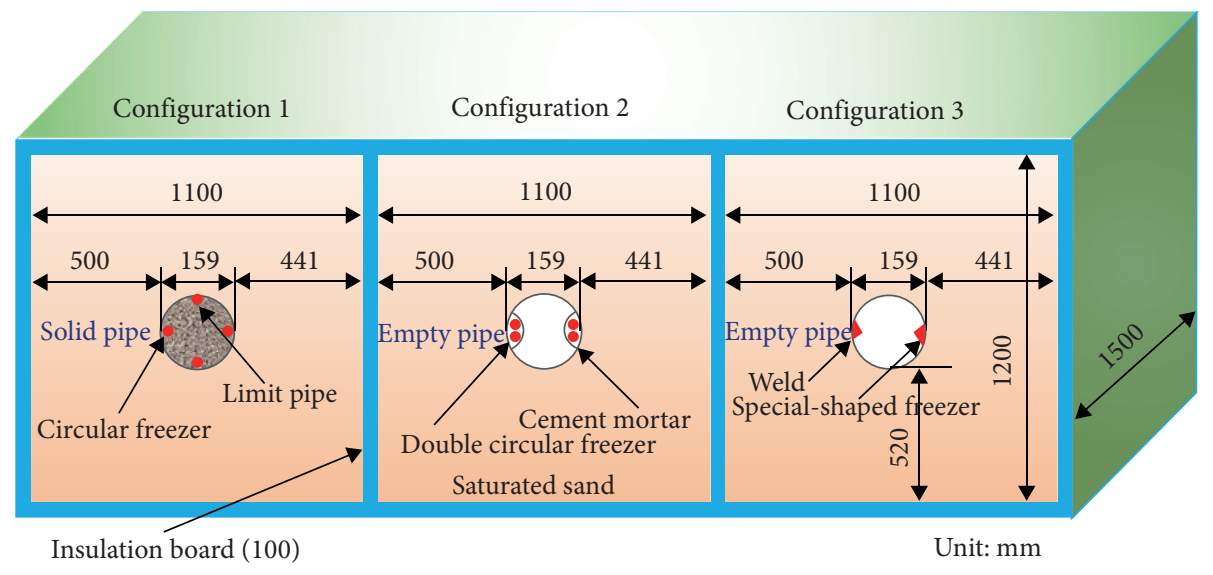

FIGURE 3: Schematic diagram of model box.

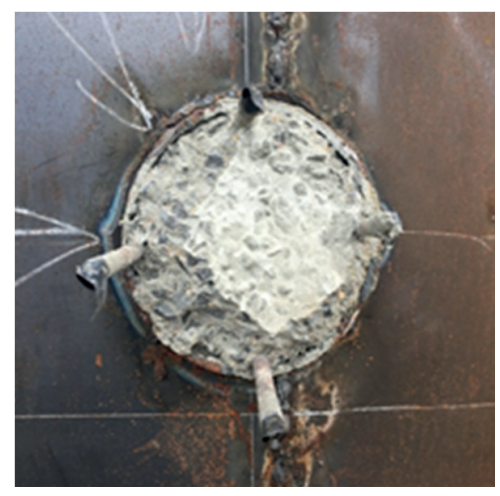

(a)

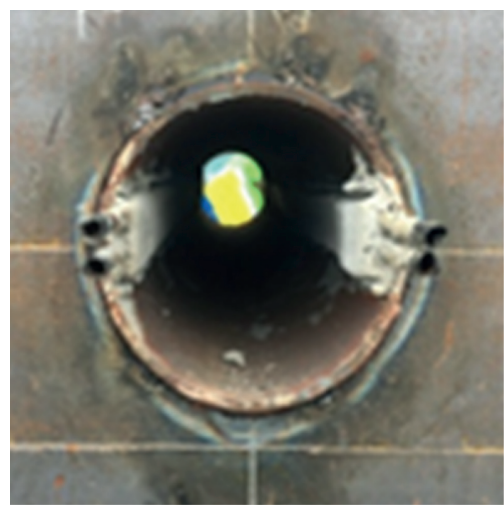

(b)

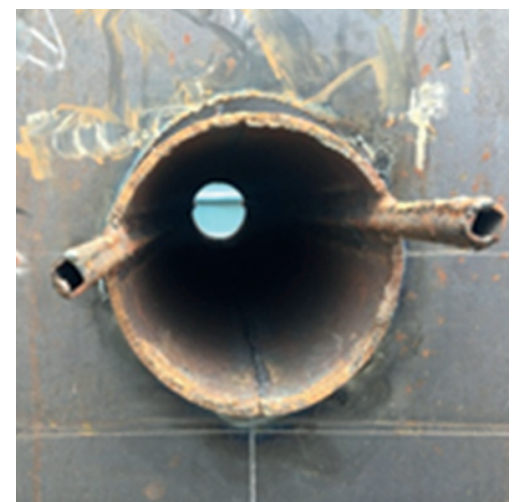

(c)

FIgURE 4: Pipe jacking layout drawing: (a) SCF; (b) EDCF; (c) ESF.

Table 2: Properties of the test soil.

\begin{tabular}{|c|c|c|c|c|c|c|}
\hline \multirow[t]{2}{*}{ Test soil } & \multirow[t]{2}{*}{$\begin{array}{c}\text { Saturated moisture } \\
(\%)\end{array}$} & \multicolumn{2}{|c|}{$\begin{array}{l}\text { Density } \\
\left(\mathrm{g} \cdot \mathrm{cm}^{-3}\right)\end{array}$} & \multirow[t]{2}{*}{$\begin{array}{l}\text { Thermal capacity } \\
\left(\mathrm{kJ} \cdot \mathrm{kg}^{-1{ }^{\circ}} \mathrm{C}^{-1}\right)\end{array}$} & \multirow[t]{2}{*}{$\begin{array}{l}\text { Thermal conductivity } \\
\qquad\left(\mathrm{W} \cdot \mathrm{m}^{-1} \mathrm{~K}^{-1}\right)\end{array}$} & \multirow[t]{2}{*}{$\begin{array}{l}\text { Freezing temperature } \\
\qquad\left({ }^{\circ} \mathrm{C}\right)\end{array}$} \\
\hline & & $\rho$ & $\rho_{d}$ & & & \\
\hline \multirow{2}{*}{$\begin{array}{l}\text { Saturated } \\
\text { sand }\end{array}$} & \multirow{2}{*}{40.29} & \multirow{2}{*}{1.435} & \multirow{2}{*}{1.317} & 1.372 & 1.475 & -10 \\
\hline & & & & 1.683 & 1.087 & 20 \\
\hline
\end{tabular}




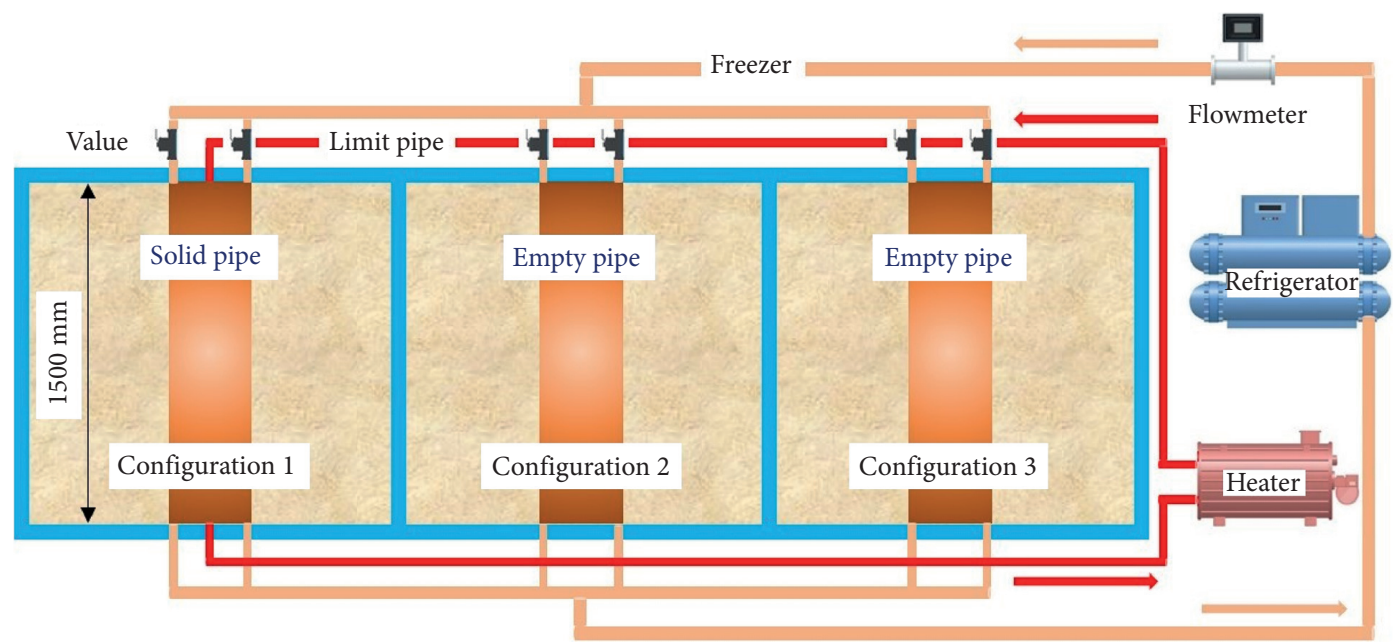

FIgURE 5: Freezing system of the model test.

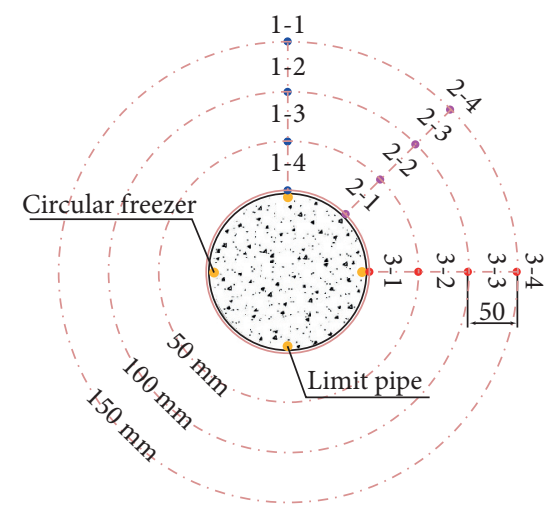

(a)

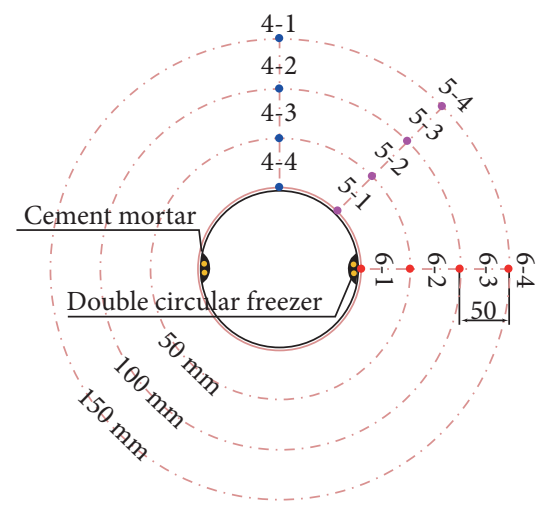

(b)

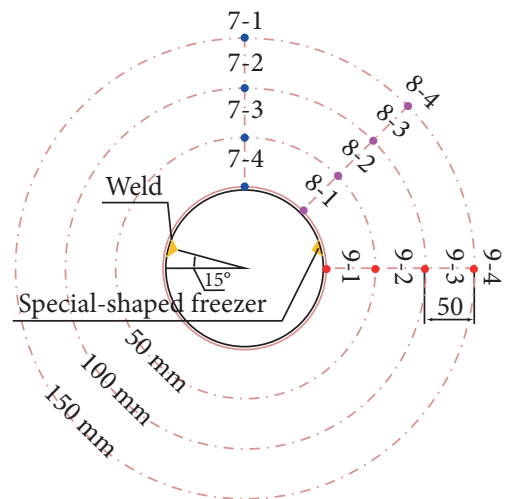

(c)

FIGURE 6: Arrangement of temperature monitoring points: (a) SCF; (b) EDCF; (c) ESF.

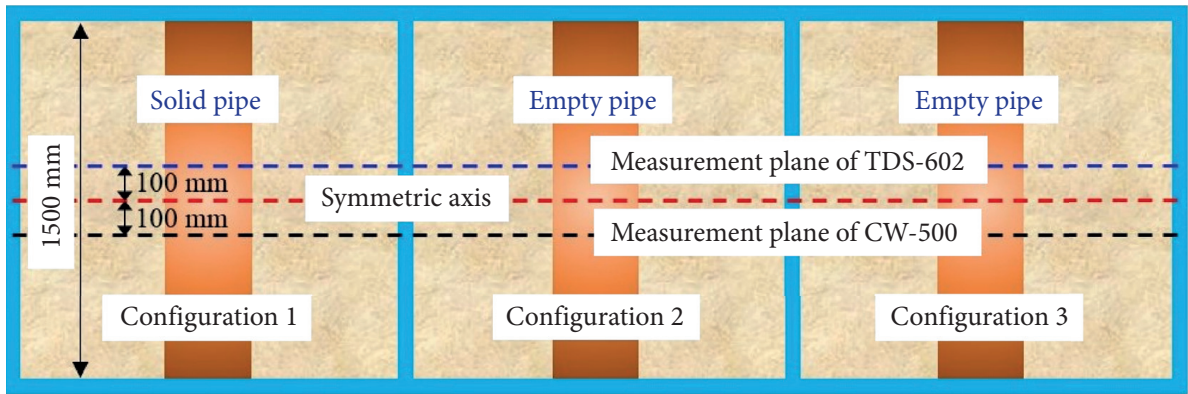

FIGURE 7: Arrangement of measurement plane.

(2) The refrigerator is opened to ensure that the brine temperature in the brine tank is fully reduced to the design temperature.
(3) The low-temperature brine system began to circulate, and all the test areas were simultaneously actively frozen. The test system comprehensively 
worked, and the temperature data were regularly monitored until the end of the first test process (the temperature of the measuring point at $100 \mathrm{~mm}$ above the pipe jacking was reduced to $-1^{\circ} \mathrm{C}$ ). At this time, the thickness of the frozen wall reached the designed thickness (360 $\mathrm{mm}$ in total).

(4) The active freezing time was set to $42 \mathrm{~h}$. The limitingpipe test was carried out to study the effect of the limiting-pipe. When the active freezing was $21 \mathrm{~h}$, the limiting brine constant temperature heater was opened, and the limiting brine circulation was carried out.

(5) After freezing to the specified test time, the refrigeration unit stopped supplying cold, and the normal temperature brine was circulated in the circular freezing pipe. All the test areas entered the forced thawing period until the saturated sand returned to normal temperature. The thawing time was controlled according to the temperature data of the measuring points.

\section{Analysis of Model Test Results}

4.1. Freezing Effect of SCF. Figure 8 shows the 'temperaturetime' curves of the monitoring points at $90^{\circ}, 45^{\circ}$, and $0^{\circ}$, respectively. The legend with ' $*$ ' represents the freezing mechanism that opens the limiting pipes after freezing for $21 \mathrm{~h}$, while the legend without '* ' represents the freezing mechanism that does not open the limiting pipes through the freezing period.

Figure 8 demonstrates that the temperature change trend of each temperature measurement point around the pipe jacking in the horizontal direction and in the $45^{\circ}$ angle direction with the horizontal direction is consistent. The temperature decreases with time, and the temperature drop is larger in the early stage of freezing and smaller in the later stage. The closer to the freezers, the greater the temperature drop is, while the farther away from the freezers it is, the smaller the temperature drop is, and the smoother the curve is

When the limit pipe is opened at $21 \mathrm{~h}$, the temperature rises, especially at the temperature measuring points $1-4$ $*, 2-1 *$, and $3-1 *$, it shows a jump rise, while it gradually tends to be stable after the limit pipe is opened for a period of time. Besides, the temperature of the temperature measurement point far from the limit pipe also increases, but its increasing range is smaller than that close to the limit pipe. The test result also shows that the temperature influences the range of the limit pipe within a $100 \mathrm{~mm}$ radius, and the limit pipe only slows down the rate of temperature decrease, but it does not increase the temperature.

Therefore, opening the limit pipe can effectively control the temperature and ensure the temperature around the pipe jacking changes evenly.

4.2. Freezing Effect of SCF, EDCF, And ESF. Figure 9 shows the 'temperature-time' curves of the monitoring points at $90^{\circ}, 45^{\circ}$, and $0^{\circ}$ in SCF, EDCF, and ESF, respectively.
Furthermore, Figure 9 demonstrates that the temperature change law is basically the same at the same monitoring direction among three freezers arrangements. They all show a 'layered' downward trend with the increasing radius. From the temperature drop trend, the early temperature drop rate of all measuring points is large, and then the later temperature drop rate gradually tends to 0 . Besides, the temperature of the ESF decreases faster in the same freezing time, and the freezing effect is better. The closer to ESF it is, the faster the early temperature drop rate is, and the greater the final cooling range is.

The following equations are provided to study the specific changes of temperature:

$$
V_{c}=\frac{t_{b}-t_{a}}{T}
$$

where $V_{c}$ is the average temperature drop rate within the selected time interval $\left({ }^{\circ} \mathrm{C} / \mathrm{h}\right) ; t_{a}$ and $t_{b}$ are the initial and final temperature of the selected time interval; $T$ is the interval of freezing time. Here, it is $21 \mathrm{~h}$.

Figure 10 illustrates that the temperature drop rate of SCF is $0.69^{\circ} \mathrm{C} / \mathrm{h}$ at $100 \mathrm{~mm}, 0.96^{\circ} \mathrm{C} / \mathrm{h}$ at $50 \mathrm{~mm}$, and $1.29^{\circ} \mathrm{C} / \mathrm{h}$ at the place close to pipe jacking. The temperature drop rate of EDCF is $0.53^{\circ} \mathrm{C} / \mathrm{h}$ at $100 \mathrm{~mm}, 0.77^{\circ} \mathrm{C} / \mathrm{h}$ at $50 \mathrm{~mm}$, and $1.08^{\circ} \mathrm{C} / \mathrm{h}$ at the place close to pipe jacking. The temperature drop rate of ESF is $0.71^{\circ} \mathrm{C} / \mathrm{h}$ at $100 \mathrm{~mm}, 0.97^{\circ} \mathrm{C} / \mathrm{h}$ at $50 \mathrm{~mm}$, and $1.34^{\circ} \mathrm{C} / \mathrm{h}$ at the place close to pipe jacking. During the period from $21 \mathrm{~h}$ to $42 \mathrm{~h}$, the temperature drop rates of the three freezers arrangements are low. The average temperature drop rate of ESF is the largest, the formation time of frozen wall is the shortest, and the freezing effect is the best. However, ESF adopts arc angle steel welding, which is difficult to operate, and considerable seam welding and overhead welding must be performed. The welding requirements are high, the freezing liquid may easily leak, and the maintenance cost is high in the later stage. Therefore, EDCF can be used instead of ESF to ensure the freezing effect of the frozen wall.

4.3. Freezing Effect of the Loop Monitoring Points. The temperature distribution in $42 \mathrm{~h}$ is obtained by combining the temperature monitoring points of SCF, EDCF, and ESF in the circumferential direction of 0,50 , 100 , and $150 \mathrm{~mm}$, and the 'temperature-time' curve is drawn as shown in Figure 11.

Figure 11 demonstrates that the temperature drop gradient at the temperature measuring point, $0 \mathrm{~mm}$ away from the pipe jacking, is the largest. Meanwhile, the temperature drop gradient at the temperature measuring point, $150 \mathrm{~mm}$ away from the pipe jacking, is the smallest. It also illustrates that the temperature drop rate at the $45^{\circ}$ oblique in the horizontal direction is greater than that at the horizontal direction, while the temperature drop rate at the horizontal direction is greater than that at the vertical direction.

4.4. Temperature Cloud Diagram. The temperature cloud diagram is drawn by Surfer software to show the evolution of the temperature field, as shown in Figure 12. 


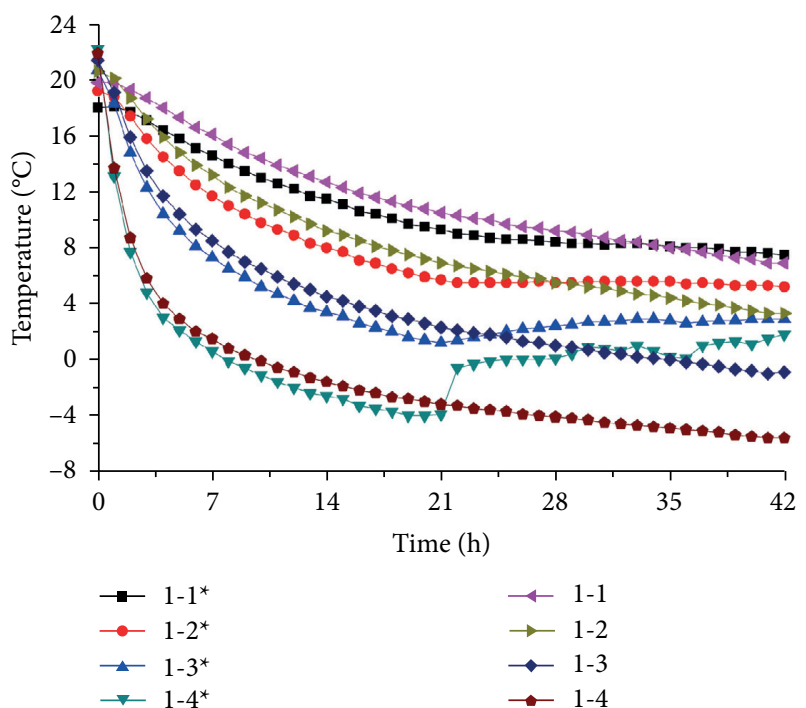

(a)

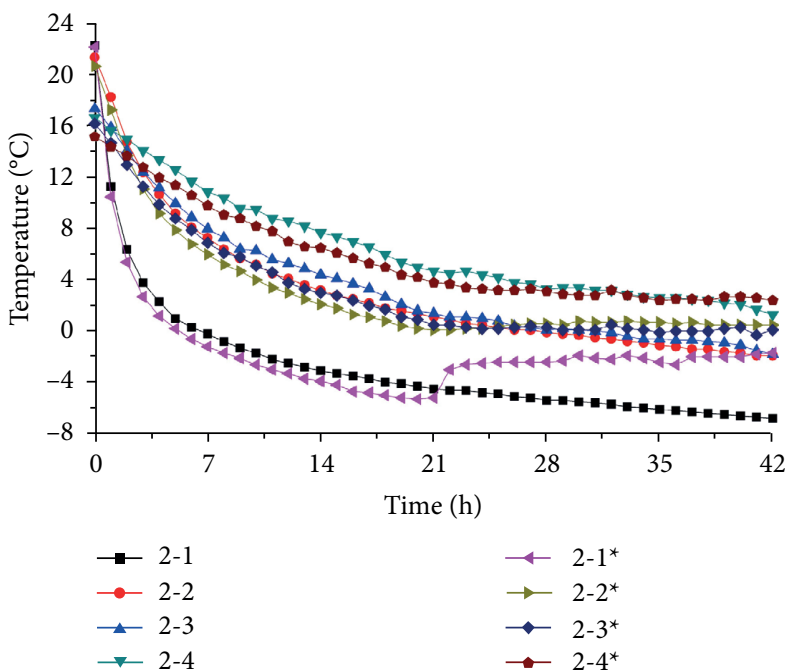

(b)

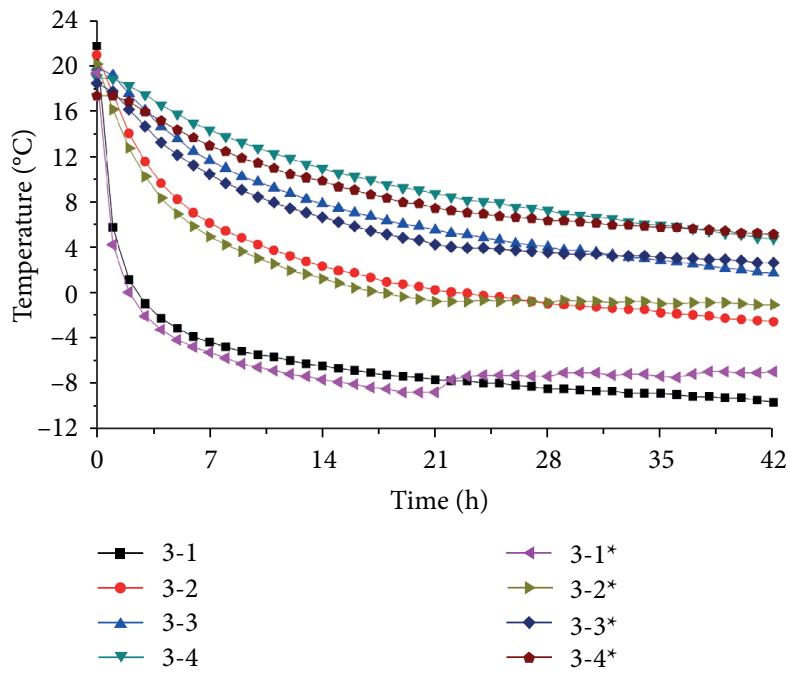

(c)

FIgURE 8: Temperature-time curves of SCF: (a) $90^{\circ}$ monitoring points; (b) $45^{\circ}$ monitoring points; (c) $0^{\circ}$ monitoring points.

Figure 12(a) shows that the temperature cloud diagram of SCF at $42 \mathrm{~h}$ is butterfly-shaped, and the frozen wall above the limit pipe is thinner than that of EDCF and ESF. The development of the frozen soil curtain is effectively controlled when the limit pipe is opened, and the central temperature of the pipe jacking is also increased. Besides, the thickness of frozen soil in three freezing configurations is similar. That is, the frozen soil above the pipe jacking is thinner than that below the pipe jacking after freezing for $21 \mathrm{~h}$, and the central temperature of ESF is the lowest.

\section{Numerical Simulation and Discussion}

5.1. Model Establishment. In order to more comprehensively understand the distribution of the freezing temperature field under the three configurations, the corresponding two-dimensional numerical models are established, as shown in Figure 13.
The heat transfer analysis module in ANSYS is adopted as the numerical simulation method using ANSYS software due to its high fidelity [20-22]. The grid system of the computational domain is created using a quadrilateral element, and its density is higher near the steel pipes and the freezers. The numerical model used in this paper has a minimum element size of $0.3 \mathrm{~mm}$, which has a good mesh element quality and faster convergence results [23].

5.2. Boundary Condition. This model has three boundaries: the first boundary is the soil boundary, which is counted as insulation, and the initial soil temperature is set to $20^{\circ} \mathrm{C}$. The second boundary and the third boundary are the freezer's wall and limiting-pipe wall, respectively, which are considered as the Dirichlet boundary condition with temperatures of $-21^{\circ} \mathrm{C}$ and $7^{\circ} \mathrm{C}$, respectively. 


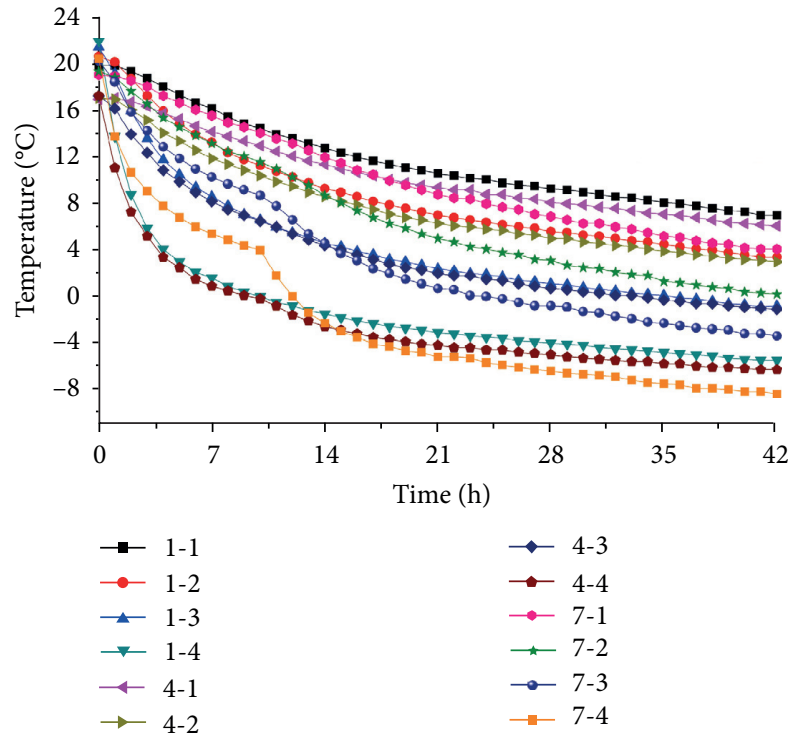

(a)

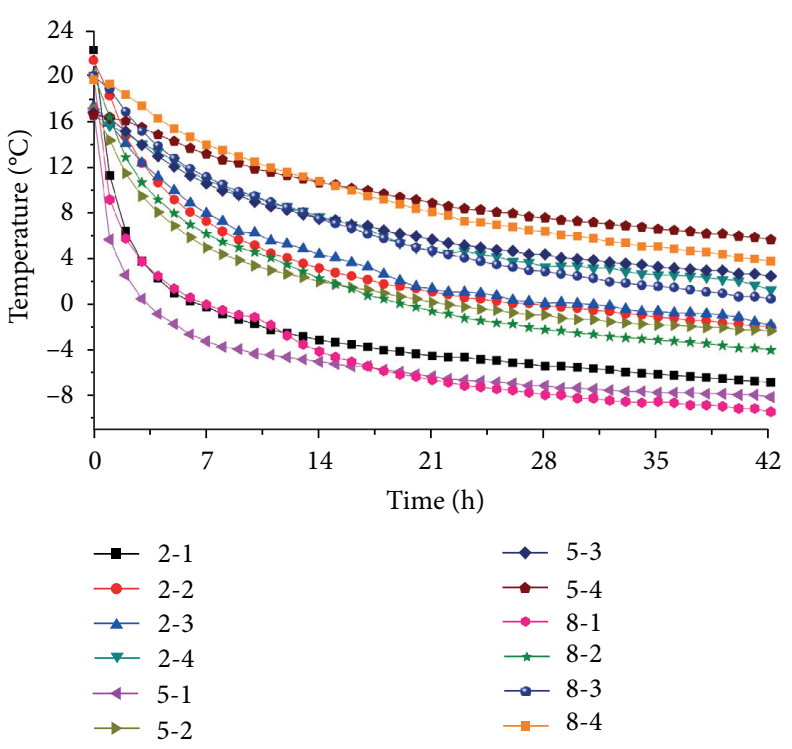

(b)

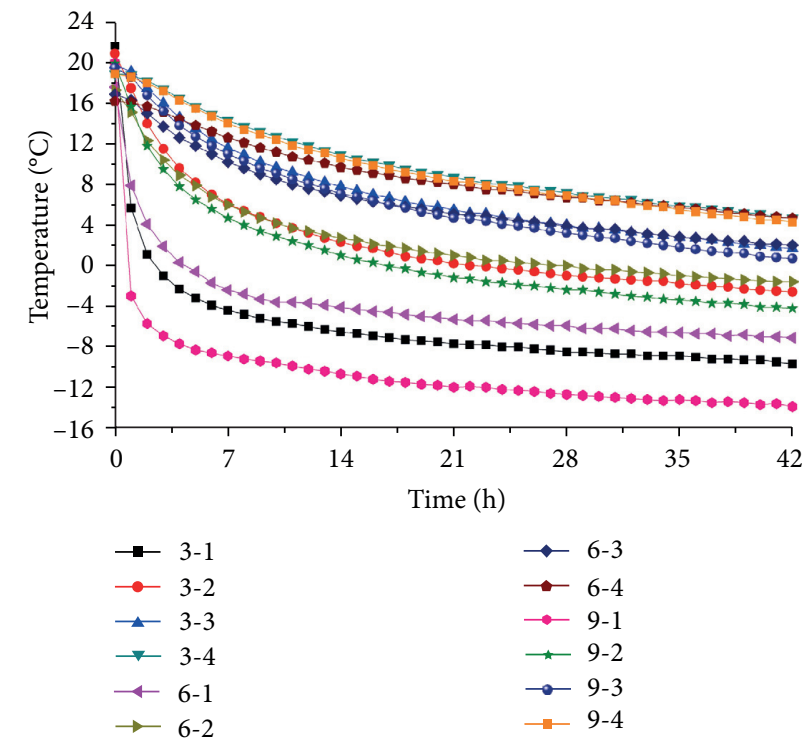

(c)

FIgURE 9: Temperature-time curves of SCF, EDCF, and ESF: (a) $90^{\circ}$ monitoring points; (b) $45^{\circ}$ monitoring points; (c) $0^{\circ}$ monitoring points.

5.3. Freezing Temperature Field Simulation Results Discussion. Figure 14 shows the freezing temperature field of three configurations at $21 \mathrm{~h}$ and $42 \mathrm{~h}$, respectively. It can be seen from Figure 13 that the temperature field around the steel pipe is evenly distributed. That is, the thickness of the frozen wall at the direction that upper, lower, left, and right of the steel pipe is basically the same, after freezing for $21 \mathrm{~h}$. In engineering application, it is hoped that the development speed of frozen wall in the connecting direction of left and right freezers will be strengthened, which is conducive to the formation of closed frozen soil curtain between pipe jacking. Meanwhile, it is hoped that the development speed of the frozen wall perpendicular to the connecting line will be weakened, which is conducive to controlling the frost heave and thaw settlement of the formation. From Figure 14(b), the thickness of the frozen wall perpendicular to the connecting line of the freezers is effectively controlled after opening the limiting pipes, which forms a butterfly-shaped temperature field, the same of measured result. Besides, the freezing effect of EDCF and ESF is almost the same, which shows EDCF can replace ESF from the perspective of the convenience of production and processing.

In order to further evaluate the reliability of the model test, the temperature measurement results at the same position in the numerical simulation and the model test are compared as shown in Figure 15.

Figure 15(a) and 15(b) show that the results of numerical simulation and model test are in good agreement. Due to the regulation of the limit pipe, the temperature at the top of SCF is finally maintained at about $4^{\circ} \mathrm{C}$, which can effectively 

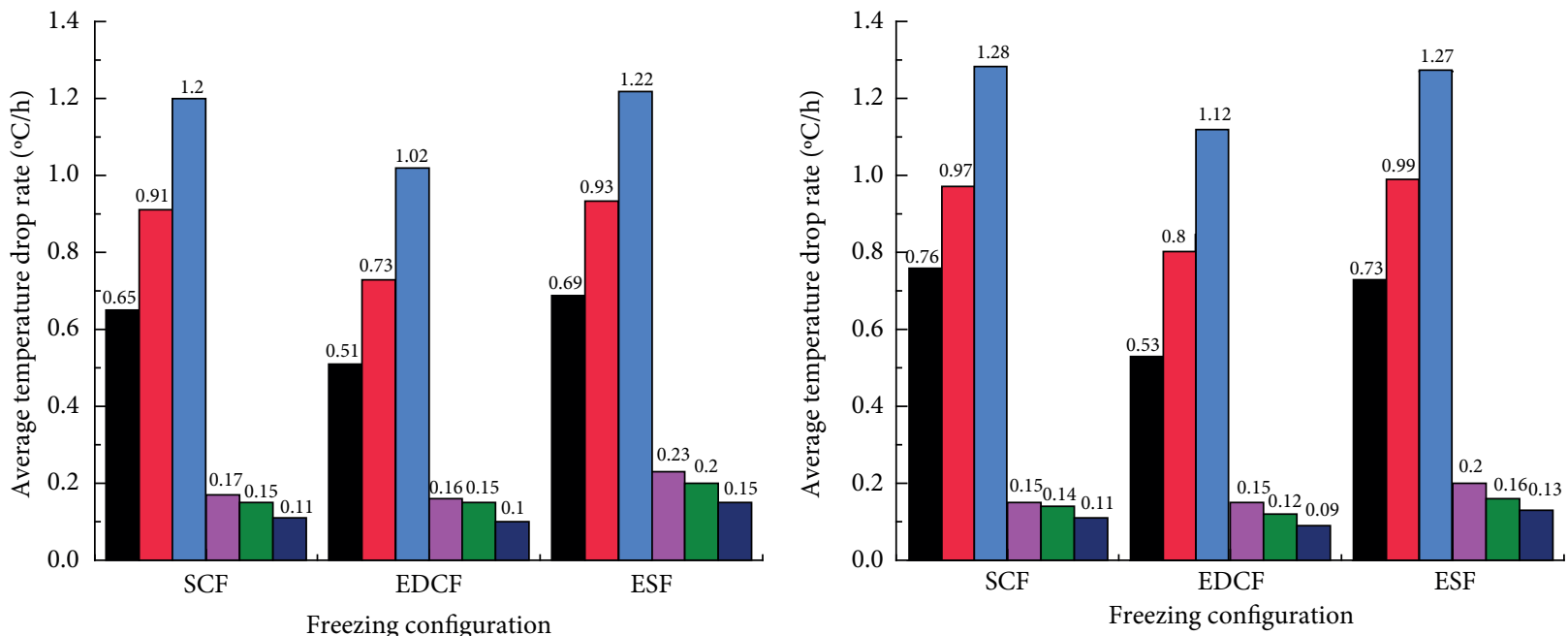

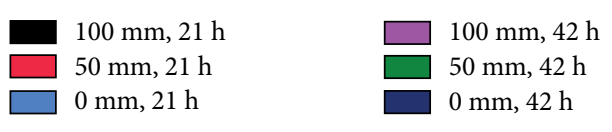

(a)

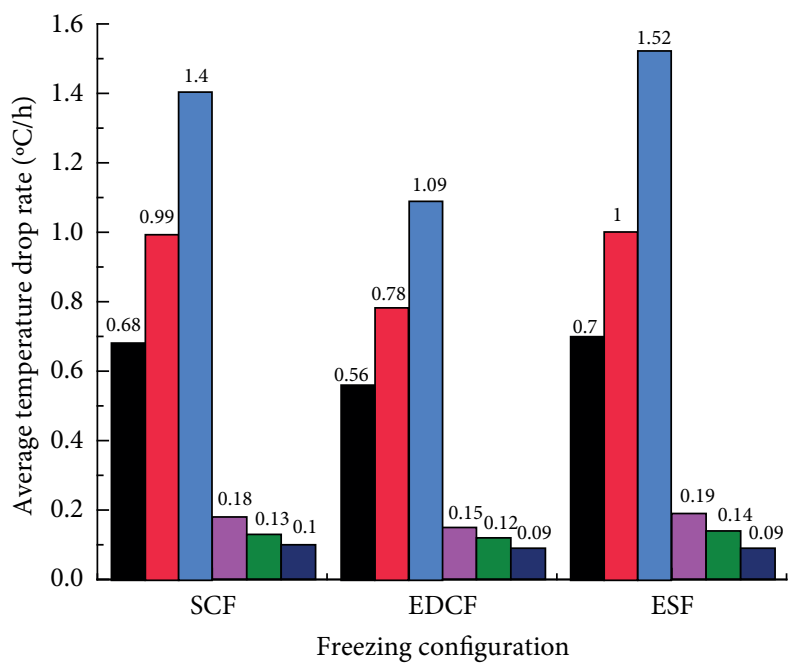

(b)

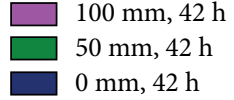



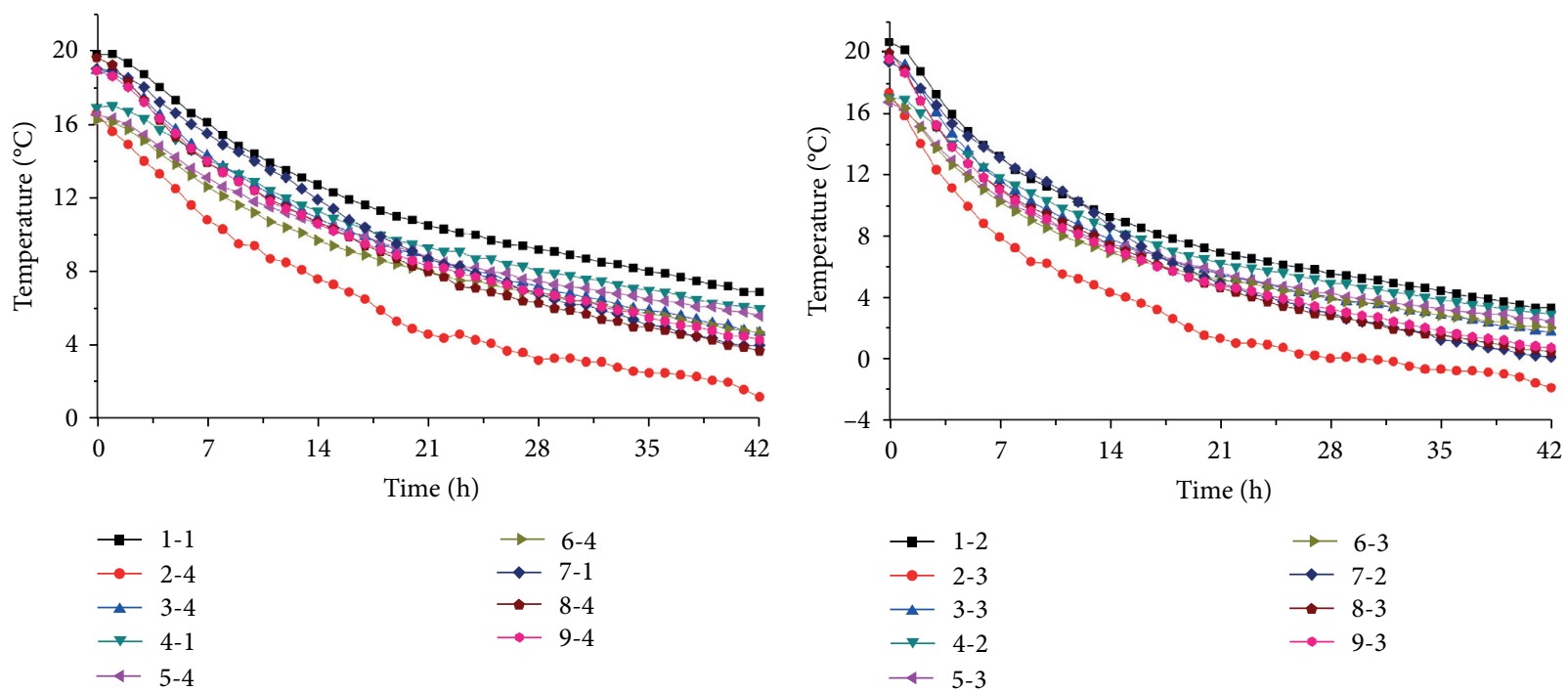

(a)
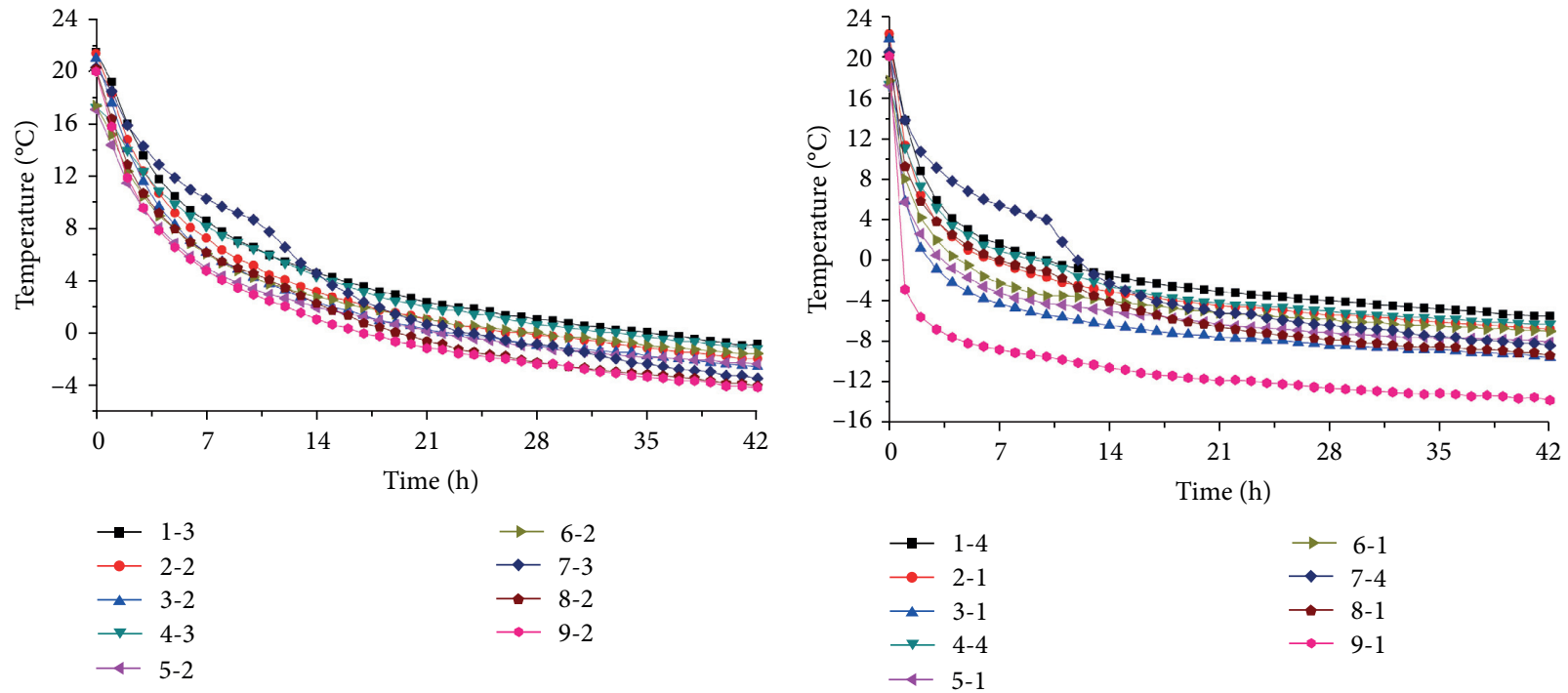

(c)

(d)

FIgURE 11: Temperature-time curves of the loop monitoring points: (a) $150 \mathrm{~mm}$; (b) $100 \mathrm{~mm}$; (c) $50 \mathrm{~mm}$; (d) $0 \mathrm{~mm}$.
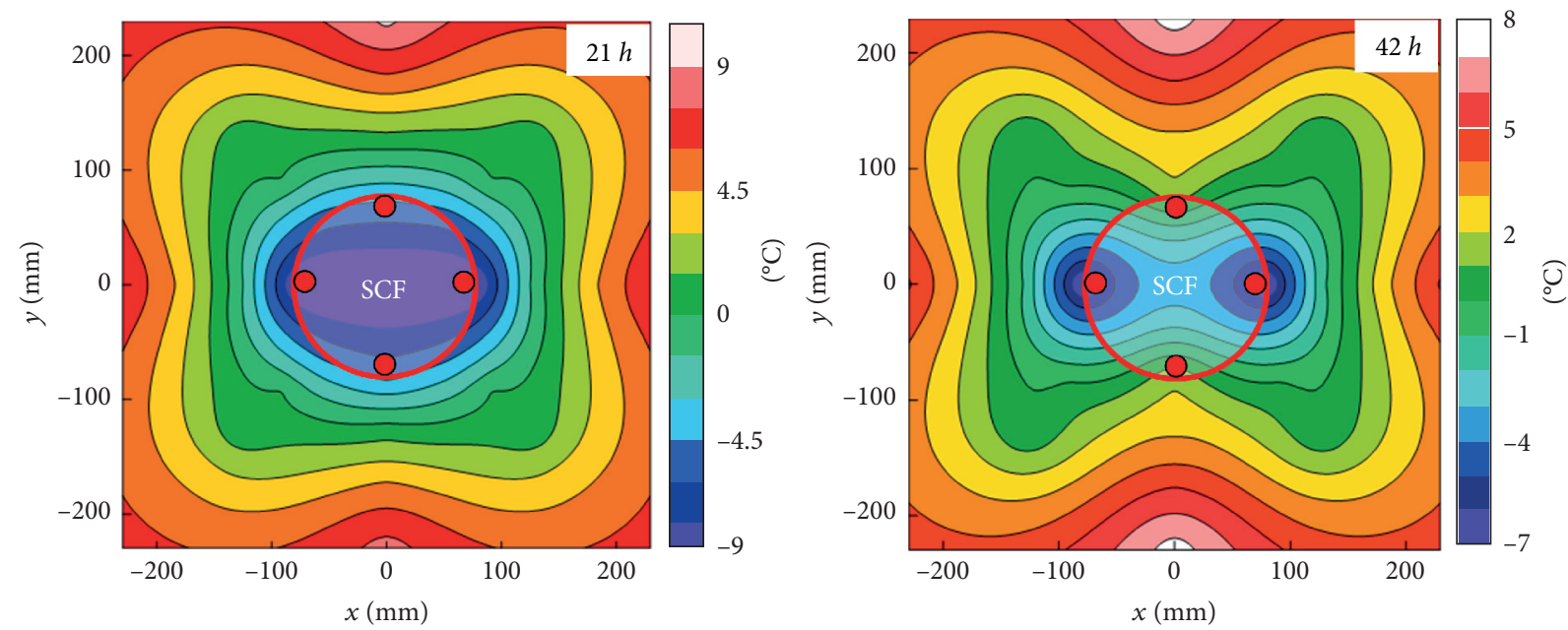

(a)

Figure 12: Continued. 

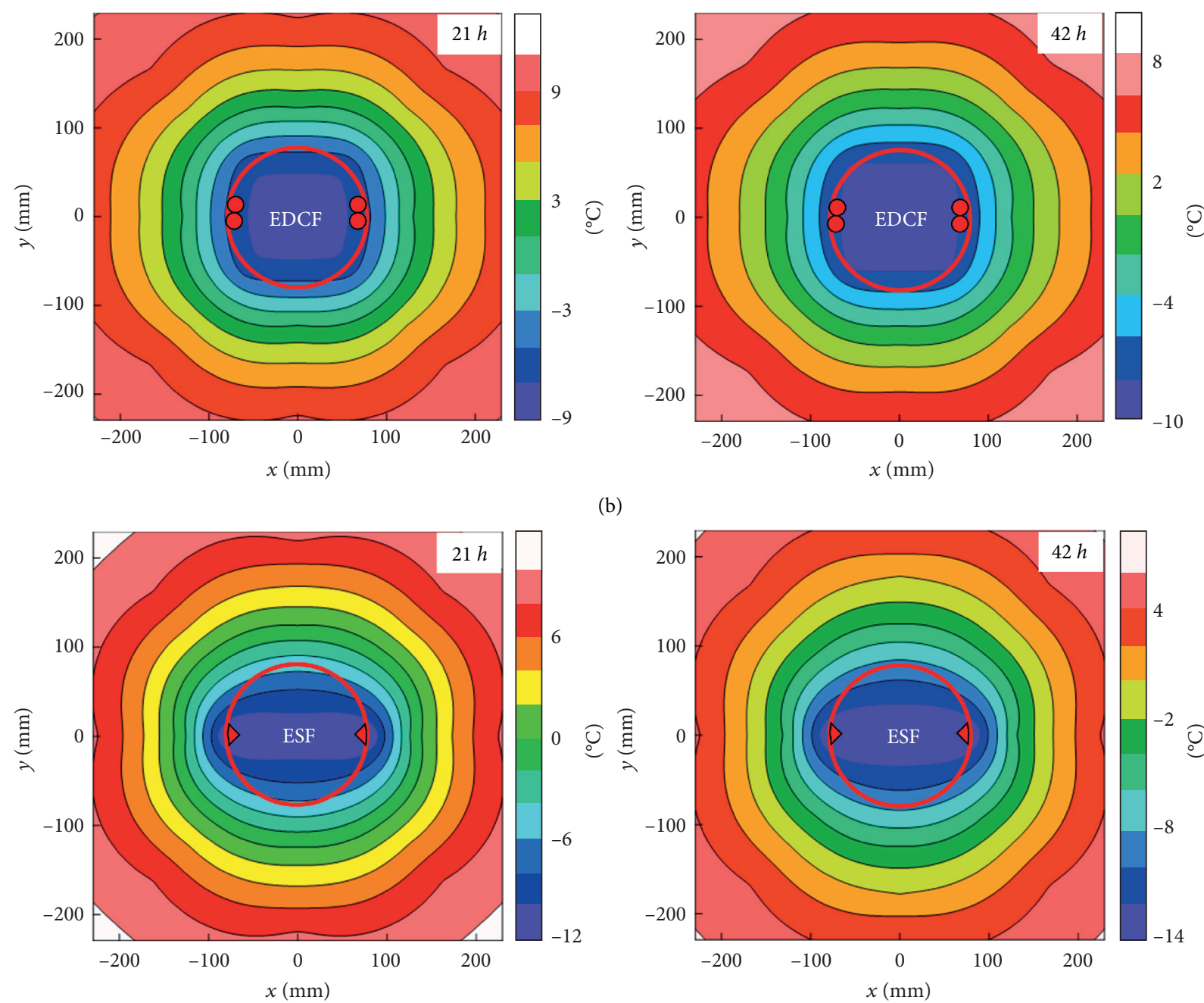

(b)

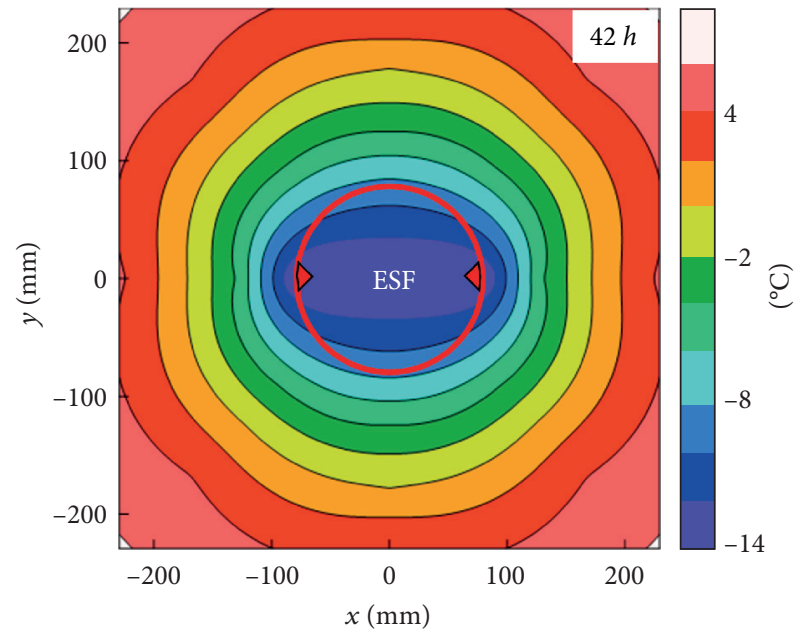

(c)

FIGURE 12: Temperature contour of the freeze-sealing pipe-roof: (a) SCF; (b) EDCF; (c) ESF.

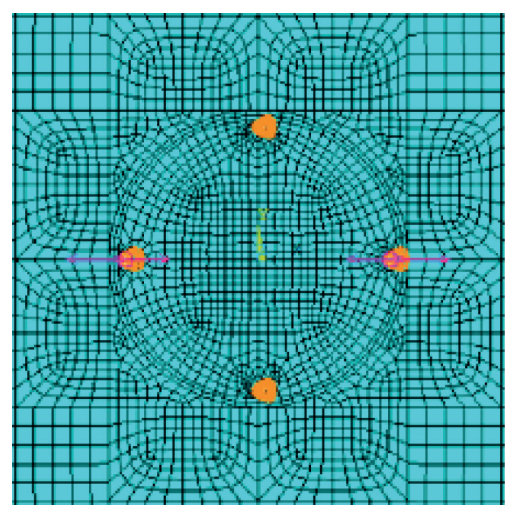

(a)

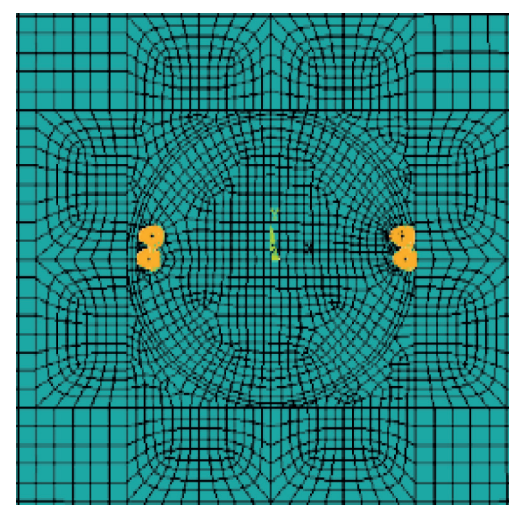

(b)

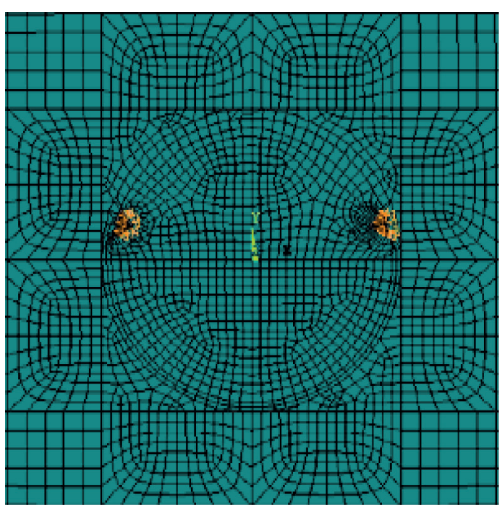

(c)

FIgURE 13: Meshing diagram: (a) SCF; (b) EDCF; (c) ESF. 


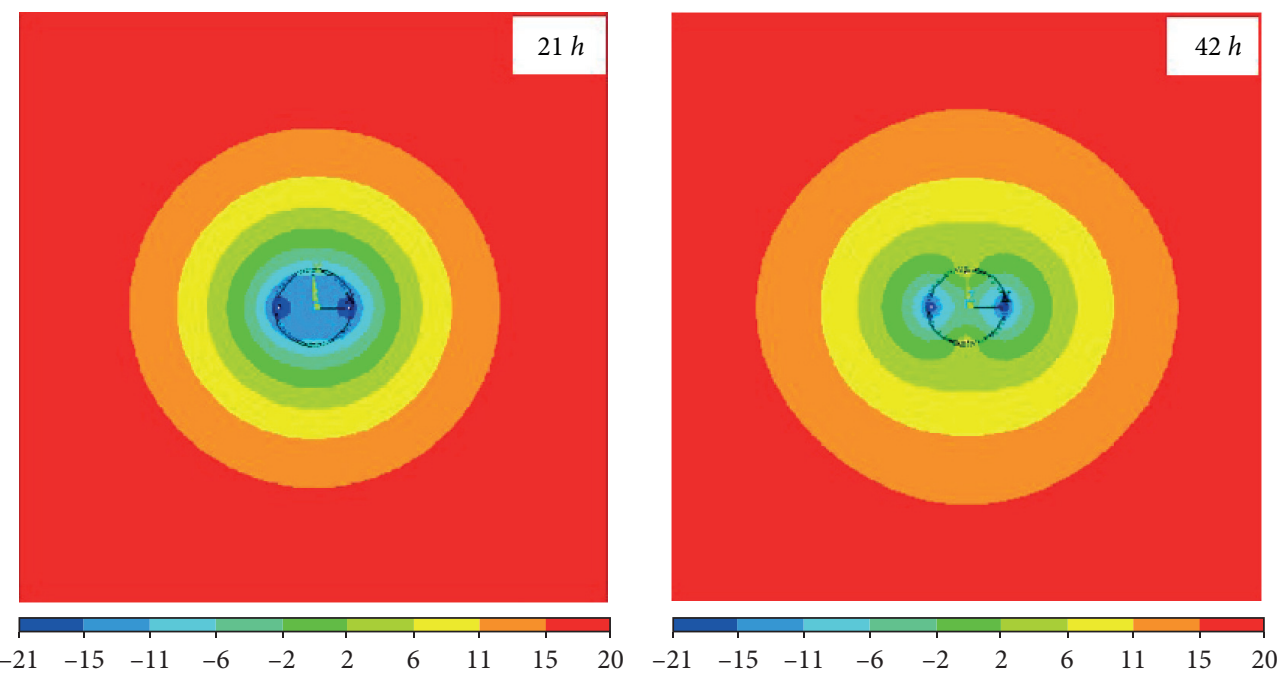

(a)
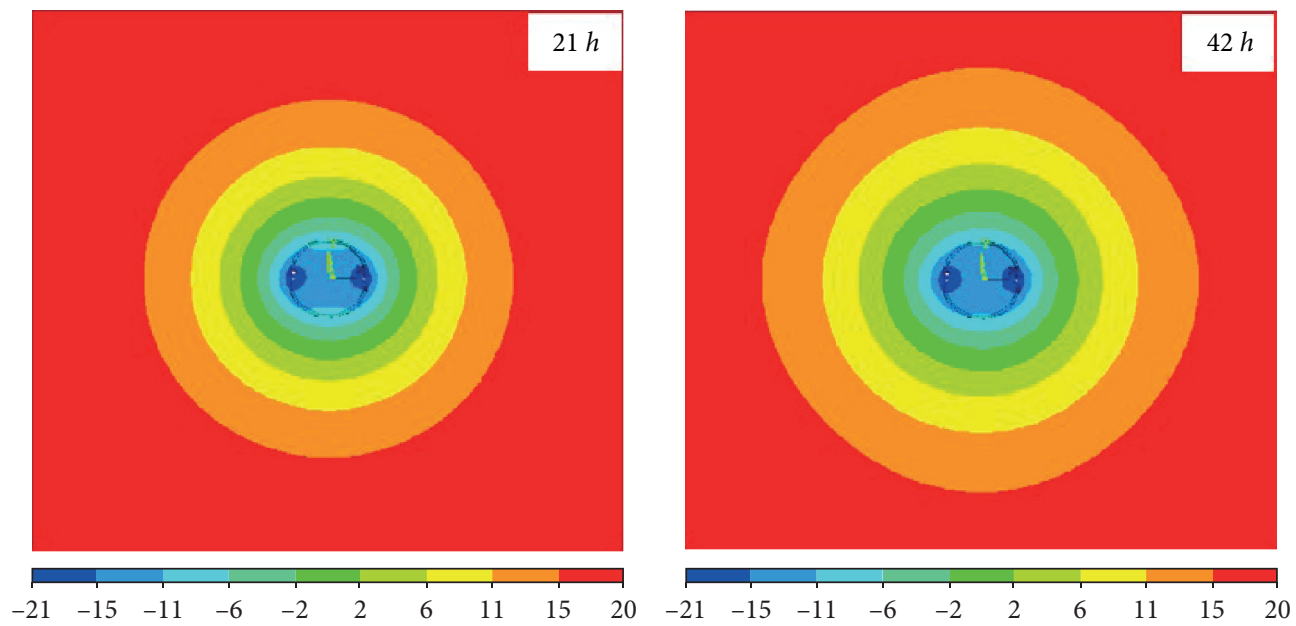

(b)
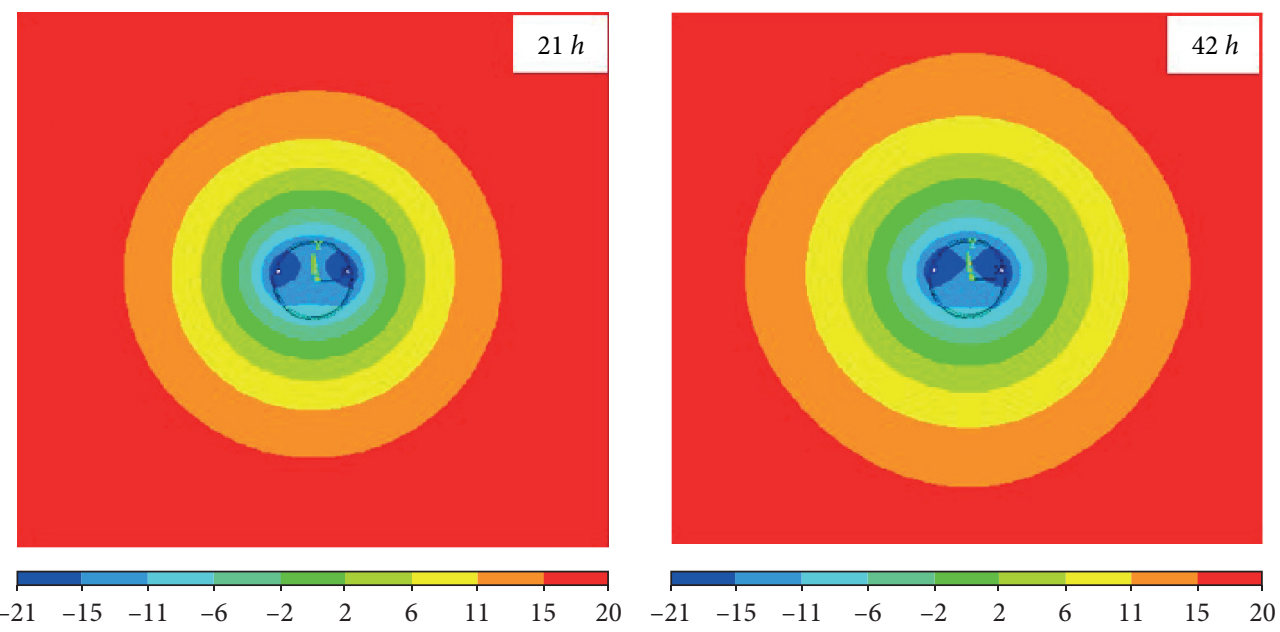

(c)

Figure 14: Freezing temperature field: (a) SCF; (b) EDCF; (c) ESF. 


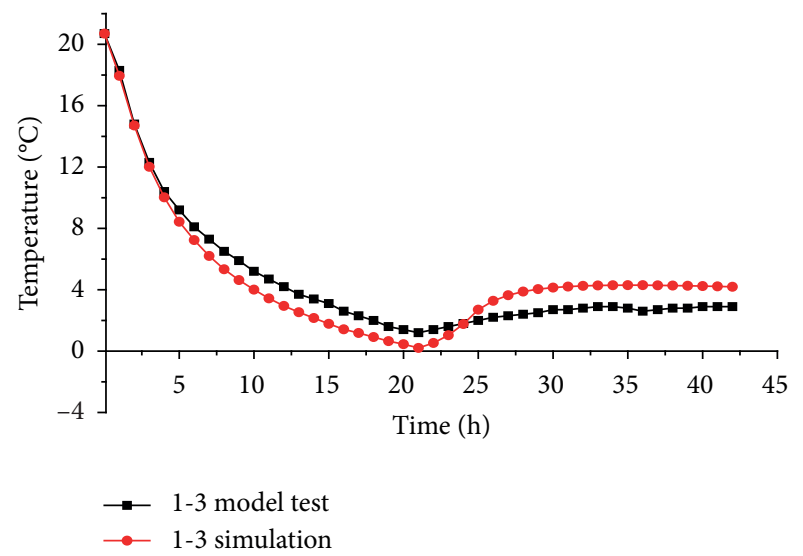

(a)

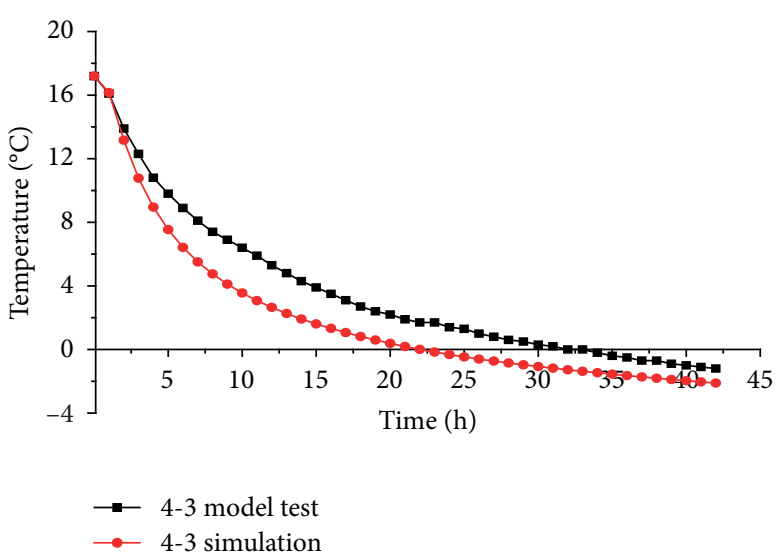

(b)

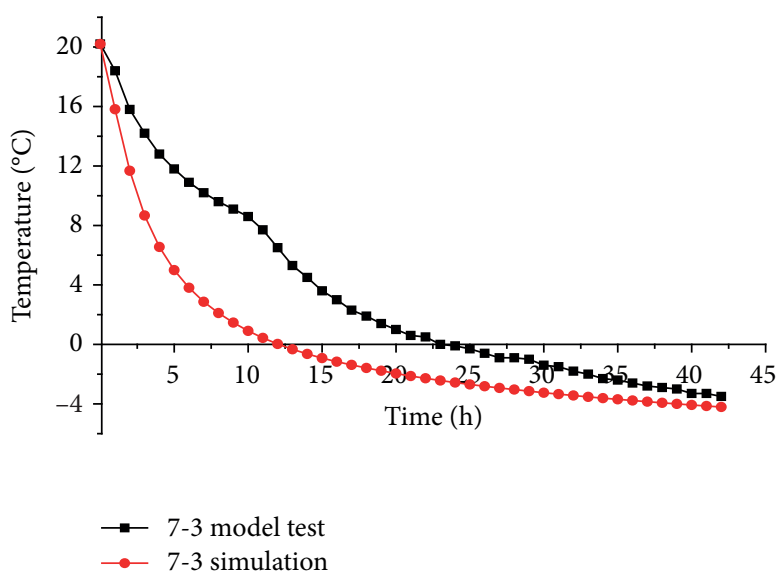

(c)

Figure 15: Temperature variation comparison diagram: (a) SCF; (b) EDCF; (c) ESF.

control the frost heave of the formation. Figure 15(c) shows a certain deviation between the model test and numerical simulation before $21 \mathrm{~h}$. The temperature in the model test is higher than that in numerical simulation. During the model test, there was brine leakage at the mouth of the specialshaped freezer, but it was repaired quickly after finding this problem. Besides, the temperature drop process of EDCF is easier than that of ESF. The freezing effect of ESF is confirmed as the best amongst the three different arrangements (SCF, EDCF, and ESF) through model tests and numerical simulations.

\section{Conclusions}

In this study, the model test and numerical simulation methods are used to conduct an in-depth analysis of the freezing temperature field under different layouts of the freeze-sealing pipe-roof single pipe to obtain the optimal structural type and layout of the freezing device. The main contents and achievements of this study are as follows:

(1) A large-scale model test system of single-pipe freezing was established on the basis of the similarity criterion, and a comparative study was conducted on the temperature field of single-pipe freezing considering three arrangement modes freezers (SCF, EDCF, and ESF). The results showed that the temperature drop rates of SCF, EDCF, and ESF were $0.69^{\circ} \mathrm{C} / \mathrm{h}, 0.53^{\circ} \mathrm{C} / \mathrm{h}$, and $0.71^{\circ} \mathrm{C} / \mathrm{h}$ at $100 \mathrm{~mm} ; 0.96^{\circ} \mathrm{C} / \mathrm{h}, 0.77^{\circ} \mathrm{C} / \mathrm{h}$, and $0.97^{\circ} \mathrm{C} / \mathrm{h}$ at $50 \mathrm{~mm} ; 1.29^{\circ} \mathrm{C} / \mathrm{h}, 1.08^{\circ} \mathrm{C} / \mathrm{h}$, and $1.34^{\circ} \mathrm{C} / \mathrm{h}$ at $0 \mathrm{~mm}$; after freezing for $21 \mathrm{~h}$. Besides, the temperature drop rates of the three arrangements of freezers are all low after freezing for $42 \mathrm{~h}$.

(2) The numerical simulation results showed that the temperature cloud diagram of SCF at $42 \mathrm{~h}$ is butterfly-shaped after opening the limit pipes, while the temperature cloud diagrams of ESF and EDCF are oval, and its results are highly consistent with the model test results.

(3) The model test results and numerical simulation results all showed that the freezing effect of ESF is the best amongst the three arrangements of freezers (SCF, EDCF, and ESF). However, the special-shaped freezer adopts arc angle steel welding, which is difficult to operate, and considerable welds and overhead welding must be performed. The welding requirements are high, and the freezing liquid may easily leak. Moreover, the maintenance cost is high in the later stage. 
Therefore, EDCF instead of ESF can be considered to ensure the freezing effect of the frozen soil wall.

\section{Data Availability}

The datasets generated and analyzed during the current study are available from the corresponding author upon reasonable request.

\section{Conflicts of Interest}

The authors declare that there are no conflicts of interest regarding the publication of this paper.

\section{Acknowledgments}

This research was supported by the National Natural Science Foundation of China (Grant no. 51778004); Research Activities Funding for Reserve Candidate of Academic and Technical Leaders of Anhui Province, China (Grant no. 2018H170); Academic Funding for Top-notch Talents in University Disciplines (Majors) of Anhui Province, China (Grant no. gxbjZD10); and Graduate Innovation Funding of Anhui University of Science and Technology (no. 2020CX2024).

\section{References}

[1] Z. Hong, X. Hu, and T. Fang, "Analytical solution to steadystate temperature field of Freeze-Sealing Pipe Roof applied to Gongbei tunnel considering operation of limiting tubes," Tunnelling and Underground Space Technology, vol. 105, Article ID 103571, 2020.

[2] A. Afshani and H. Akagi, "Artificial ground freezing application in shield tunneling," Japanese Geotechnical Society Special Publication, vol. 3, no. 2, pp. 71-75, 2015.

[3] L. Zheng, Y. Gao, Y. Zhou, T. Liu, and S. Tian, "A practical method for predicting ground surface deformation induced by the artificial ground freezing method," Computers and Geotechnics, vol. 130, Article ID 103925, 2021.

[4] Q. Yan, W. Wu, C. Zhang, S. Ma, and Y. Li, "Monitoring and evaluation of artificial ground freezing in Metro tunnel construction-A case study," KSCE Journal of Civil Engineering, vol. 23, no. 5, pp. 2359-2370, 2019.

[5] J. Hu, Y. Liu, Y. Li, and K. Yao, "Artificial ground freezing in tunnelling through aquifer soil layers: a case study in nanjing Metro line 2," KSCE Journal of Civil Engineering, vol. 22, no. 10, pp. 4136-4142, 2018.

[6] X. Hu, S. Deng, and H. Ren, "In situ test study on freezing scheme of freeze-sealing pipe roof applied to the Gongbei tunnel in the Hong Kong-Zhuhai-Macau Bridge," Applied Sciences, vol. 7, no. 1, p. 27, 2016.

[7] Y. Sun, F. Wu, W. J. Sun, H. M. Li, and G. J. Shao, "Two underground pedestrian passages using pipe jacking: case study," Journal of Geotechnical and Geoenvironmental Engineering, vol. 145, no. 2, Article ID 05018004, 2019.

[8] S. L. Shen, Q. L. Cui, C. E. Ho, and Y. S. Xu, "Ground response to multiple parallel microtunneling operations in cemented silty clay and sand," Journal of Geotechnical and Geoenvironmental Engineering, vol. 145, no. 5, Article ID 04016001, 2016.

[9] L. Zhen, J.-J. Chen, P. Qiao, and J.-H. Wang, "Analysis and remedial treatment of a steel pipe-jacking accident in complex underground environment," Engineering Structures, vol. 59, no. 2, pp. 210-219, 2014.

[10] X. D. Hu, X. Y. Li, Y. H. Wu, L. Han, and C. B. Zhang, "Effect of water-proof in Gongbei Tunnel by freeze-sealing pipe roof method with field temperature data," Chinese Journal of Geotechnical Engineering, vol. 41, no. 12, pp. 2207-2214, 2019.

[11] X. Hu, Z. Hong, and T. Fang, "Analytical solution to steadystate temperature field with typical freezing tube layout employed in freeze-sealing pipe roof method," Tunnelling and Underground Space Technology, vol. 79, pp. 336-345, 2018.

[12] Y. Duan, C. Rong, H. Cheng, H. Cai, Z. Wang, and Z. Yao, "Experimental and numerical investigation on improved design for profiled freezing-tube of FSPR," Processes, vol. 8, no. 8, p. 992, 2020.

[13] X. Hu, T. Fang, J. Chen, H. Ren, and W. Guo, "A large-scale physical model test on frozen status in freeze-sealing pipe roof method for tunnel construction," Tunnelling and Underground Space Technology, vol. 72, pp. 55-63, 2018.

[14] Z. Zhou, J. Zhao, Z. Tan, and X. Zhou, "Mechanical responses in the construction process of super-large cross-section tunnel: a case study of Gongbei tunnel," Tunnelling and Underground Space Technology, vol. 115, Article ID 104044, 2021.

[15] Y. Qi, J. Zhang, H. Yang, and Y. Song, “Application of artificial ground freezing technology in modern urban underground engineering," Advances in Materials Science and Engineering, vol. 2020, Article ID 1619721, 12 pages, 2020.

[16] Y. Liu, K.-Q. Li, D.-Q. Li, X.-S. Tang, and S.-X. Gu, “Coupled thermal-hydraulic modeling of artificial ground freezing with uncertainties in pipe inclination and thermal conductivity," Acta Geotechnica, vol. 2, 2021.

[17] M. Vitel, A. Rouabhi, M. Tijani, and F. Guérin, "Modeling heat transfer between a freeze pipe and the surrounding ground during artificial ground freezing activities," Computers and Geotechnics, vol. 63, pp. 99-111, 2015.

[18] G. X. Cui, Similarity Theory and Model Test, China University of Mining and Technology Press, Xuzhou, China, 1990.

[19] Z. S. Yao, H. Cheng, and H. B. Xia, "Model test study on frostheaving force in retaining structure of row-piles and frozen soil wall of super deep foundation pit," Chinese Journal of Rock Mechanics and Engineering, vol. 26, no. 2, pp. 415-420, 2007.

[20] H. B. Cai, H. Cheng, Z. S. Yao, and H. Wang, "Numerical analysis of ground displacement due to orthotropic frost heave of frozen soil in freezing period of tunnel," Chinese Journal of Rock Mechanics and Engineering, vol. 34, pp. 1667-1676, 2015.

[21] Y. M. Lai, S. Y. Liu, Z. W. Wu, and W. B. Yu, "Approximate analytical solution for temperature fields in cold regions circular tunnels," Cold Regions Science and Technology, vol. 34, pp. 43-49, 2002.

[22] X.-D. Hu, T. Fang, and Y.-G. Han, "Mathematical solution of steady-state temperature field of circular frozen wall by singlecircle-piped freezing," Cold Regions Science and Technology, vol. 148, pp. 96-103, 2018.

[23] R. Hong, H. Cai, and M. Li, "Integrated prediction model of ground Surface deformation during tunnel construction using local horizontal freezing technology," Arabian Journal for Science and Engineering, vol. 10, 2021. 